\title{
Evaluation of four clinical laboratory parameters for the diagnosis of myalgic encephalomyelitis
}

\author{
Kenny L. De Meirleir ${ }^{1 \dagger}$, Tatjana Mijatovic ${ }^{2 \dagger}$, Krishnamurthy Subramanian ${ }^{3}$, Karen A. Schlauch ${ }^{4}$ \\ and Vincent C. Lombardi ${ }^{*^{*}}$ (D)
}

\begin{abstract}
Background: Myalgic encephalomyelitis (ME) is a complex and debilitating disease that often initially presents with flu-like symptoms, accompanied by incapacitating fatigue. Currently, there are no objective biomarkers or laboratory tests that can be used to unequivocally diagnosis ME; therefore, a diagnosis is made when a patient meets series of a costly and subjective inclusion and exclusion criteria. The purpose of the present study was to evaluate the utility of four clinical parameters in diagnosing ME.
\end{abstract}

Methods: In the present study, we utilized logistic regression and classification and regression tree analysis to conduct a retrospective investigation of four clinical laboratory in $140 \mathrm{ME}$ cases and 140 healthy controls.

Results: Correlations between the covariates ranged between $[-0.26,0.61]$. The best model included the serum levels of the soluble form of CD14 (sCD14), serum levels of prostaglandin $E 2$ ( $\left.P G E_{2}\right)$, and serum levels of interleukin 8 , with coefficients $0.002,0.249$, and 0.005 , respectively, and p-values of $3 \times 10^{-7}, 1 \times 10^{-5}$, and $3 \times 10^{-3}$, respectively.

Conclusions: Our findings show that these parameters may help physicians in their diagnosis of ME and may additionally shed light on the pathophysiology of this disease.

Keywords: ME/CFS, Diagnostic, IL-8, PGE2, sCD14, CD57, Chronic fatigue

\section{Background}

Myalgic encephalomyelitis is a heterogeneous illness often characterized by a number of physical symptoms and comorbid conditions such as systemic inflammation, neurocognitive abnormalities, innate immune activation, and gastrointestinal issues [1]. Current estimates indicate that up to 4 million individuals in the U.S. are afflicted with ME [2], with an annual productivity loss in excess of $\$ 23$ billion in the United States alone [3], underscoring the significant impact of ME as a major public health concern both economically and socially.

\footnotetext{
*Correspondence: vlombardi@med.unr.edu

${ }^{\dagger}$ Kenny L. De Meirleir and Tatjana Mijatovic contributed equally to this work

${ }^{5}$ Department of Microbiology and Immunology, University of Nevada,

Reno, School of Medicine, Reno, NV, USA

Full list of author information is available at the end of the article
}

Little is known regarding the etiology of ME; however, a number of potential triggers or stressors are typically reported to coincide with the onset of the disease including viral or flu-like symptoms, chemical exposure, physical trauma, or emotional distress [4-6]. Based on genome-wide association studies (GWAS) and familial studies, a genetic predisposition has also been suggested to play a role in the disease [7-10]. With the exception of perhaps exercise intolerance and general inflammation, no ubiquitous physical symptoms or diagnostic biomarkers have been identified; therefore, a diagnosis is primarily based on meeting a number of inclusion and exclusion criteria [11, 12]. As such, ME is often considered a "heterogenous" disease and this limitation has hindered the identification of nonsubjective biomarkers [13]. Compounding this issue, current research suggests that previously described potential biomarkers, such as cytokines, 
change over time [14] and may vary depending on illness duration [15] and severity [16].

In light of the heterogenous nature of ME, a biomarker that separates patients into more homogenous subgroups, based on clinical presentation would be useful; albeit, some progress has been made in this area. For instance, Naviaux and coworkers conducted a metabolomics study of ME cases and controls and identified a profile, characterized by decreased circulating ceramides [17]. A later study by Nagy-Szakal et al. elaborated that the subset of ME cases who present with irritable bowel syndrome (IBS) comorbidity have increased plasma ceramides [18]. When taken together, these studies imply that serum or plasma ceramides may have the necessary sensitivity to subgroup ME cases based on gastrointestinal (GI) comorbidity, although these observations will need to be evaluated against diseases with overlapping symptomology to show specificity.

While not universally prevalent, a small number of immunological parameters have been frequently reported to associate with subgroups of ME cases including natural killer (NK) cell dysfunction and inflammatory cytokine production. For these reasons, as well as other, it is generally accepted that ME has immunological underpinnings [19-23]. Currently, the mechanisms responsible for these observations remain elusive, but if identified, this knowledge would provide a greater understanding of ME pathology, potentially leading to effective treatment options.

In the present study, we investigated four immunological parameters that were chosen based on the following rationale: Subjects with ME are often characterized by coinfections; therefore, we analyzed the chemotactic factor interlerukin-8 (IL-8), which is produced by macrophages and, to a lesser extent, by other cells in response to infection. In light of the GI comorbidity, commonly associated with ME we measured the soluble form of CD14 (sCD14); a surrogate marker of bacterial translocation in the gut [48]. Orthostatic intolerance and atypically cerebral vasoconstriction following orthostatic challenge are often observed in subjects with ME [24, 25]. Additionally, females commonly report exasperated symptoms of premenstrual syndrome and Th1 suppression is commonly observed as well, all of which are associated with prostaglandin E2 ( $\left.\mathrm{PGE}_{2}\right)$ production [26-28]. Lastly, CD57 expression on natural killer (NK) cells is an end-stage marker for their maturation [29]. Previous studies suggest that circulating $\mathrm{CD} 57^{+} / \mathrm{CD}^{-} \mathrm{NK}$ cells are increased in association with chronic infections but are downregulated in several autoimmune diseases [29]. Mounting evidence suggests that ME may have an "autoimmune-like" etiology [30-35]; therefore, we included circulating $\mathrm{CD} 57^{+} / \mathrm{CD}^{-} \mathrm{NK}$ cells in our analysis.

\section{Methods}

\section{Study design}

Retrospective analyses of existing clinical data were conducted under a HIPAA authorization waiver, as determined by the University of Nevada, Reno Institutional Review Board (IRB) [Protocol 1213405-1]. From these data, four clinical parameters were chosen for investigation based on their potential diagnostic utility and their ability to subgroup ME cases, given their common symptoms and medical anamnesis. In the present study, the following data were collected: absolute counts of peripheral $\mathrm{CD} 7^{+} / \mathrm{CD}^{-}$lymphocytes; serum levels of IL-8, (also known as CXCL8); serum levels of the soluble form of CD14 (sCD14) and serum levels of prostaglandin E2 $\left(\mathrm{PGE}_{2}\right)$. Age and gender were also recorded to address potential age- and gender-related contributions.

\section{Clinical data}

Whole blood ( $\mathrm{K}_{2}$ EDTA anticoagulant) and serum was collected by venipuncture from ME cases at the Himmunitas Foundation clinic (Brussels, Belgium), and transported the same day to R.E.D. Laboratories (Zellik, Belgium) for clinical analysis. These analyses were conducted as part of the patient's initial clinical work-up. Laboratory results were search from a sequential accession series starting in 2013. From these data the first 70 female and 71 male cases who met the following inclusion criteria were selected: all four parameters were evaluated for each subject using blood drawn on the same day; and each subject had received a diagnosis of ME according the Canadian Consensus Criteria for ME [11]. Data from these 70 female cases (age median 44 years; age range 16-68 years) and 71 male cases (age median 43 years; age range $15-67$ years) were used in the analysis, as well as data from 70 female (age median 44.5 years; age range 14-86 years) and 70 male (age median 43.5 years; age range $18-70$ years) healthy subjects. Control subjects met the following inclusion criteria: Normal white blood cell count, no inflammation, (C-reactive protein $<1 \mathrm{mg} / \mathrm{L}$ ), and no clinical history of chronic immune disease or diabetes.

\section{$\mathrm{PGE}_{2}$ quantitative determination in human serum}

Serum levels of $\mathrm{PGE}_{2}$ were evaluated using the Detect $\mathrm{X}^{\circledR}$ Prostaglandin E2 Immunoassay kit (Arbor Assay, Michigan, USA) according to the manufacturer's instructions. The concentration of $\mathrm{PGE}_{2}$ in each diluted sample was calculated using a four-parameter logistic regression fitting routine provided with the microplate reader analysis software (BioRad, Nazareth, Belgium) and the neat concentrations of each sample were obtained by multiplying this value by the dilution factor. Normal values for the assay were previously determined by analyzing 79 
Table 1 Demographic information and clinical values for the respective study groups

\begin{tabular}{|c|c|c|c|c|c|c|}
\hline & Age range & Age mean & CD57 (cells/mL) & $\mathrm{sCD} 14(\mathrm{ng} / \mathrm{mL})$ & $\mathrm{PGE}_{2}$ & IL-8 (pg/mL) \\
\hline Reference range: & & & $60-360$ & $1430-2800$ & $\begin{array}{l}0.1-2.81^{*} \\
0.17-6.45\end{array}$ & $0-15$ \\
\hline Female controls $(\mathrm{N}=70)$ & $14-86$ & 44.5 & 76 & 2654 & 1.83 & 13 \\
\hline Female cases $(\mathrm{N}=69)$ & $16-68$ & 44 & 46 & 3425 & 7.97 & 1156 \\
\hline Male controls $(N=70)$ & $18-70$ & 43.5 & 103 & 2365 & 4.00 & 14 \\
\hline Male cases $(N=71)$ & $15-67$ & 43 & 58 & 2918 & 11.80 & 697 \\
\hline
\end{tabular}

* $\mathrm{PGE}_{2}$ values are given as a ratio to a reference range median; ranges are for females (top) and males (bottom)

de-identified samples from 42 female and 37 male healthy subjects referred to the laboratory for a general check-up screening. Statistical analyses established that no differences in $\mathrm{PGE}_{2}$ were linked to age; however, noticeable differences were linked to gender. Therefore, gender-specific median values were established. These median values were used to standardize all values in the format of a ratio. The control range was established using the 10th (P10) and 90th (P90) percentile of the healthy population as references values, i.e. P10 ratio to median as lower limit and the P90 ratio to median as upper limit (Table 1).

\section{Quantification of IL-8 and SCD14 serum levels}

Serum levels of IL-8 were assessed as part of a multiplex cytokine panel using the BD Cytometric Bead Array Human Inflammatory Cytokines Kit on a BD FACS Canto $\mathrm{II}^{\mathrm{TM}}$ flow cytometer (Becton-Dickinson Biosciences, San José, CA, USA). Absolute values were calculated from a standard curve using FCAP Array ${ }^{\text {TM }}$ software and interassay controls were used for each batch. Similarly, serum levels of sCD14 were assessed using BD Cytometric Bead Array Human Soluble CD14 Flex Set on the same cytometer, according to the manufacturer's instructions. Positive controls and inter-assay controls were run for each batch, and unknown values were calculated from a standard curve generated using protein standards of known concentrations.

\section{Quantification of peripheral $\mathrm{CD} 57^{+} / \mathrm{CD}^{-}$lymphocytes}

Absolute $\mathrm{CD} 57^{+} / \mathrm{CD}^{-}$lymphocytes counts were evaluated with a BD FACS Canto $\mathrm{II}^{\mathrm{TM}}$ flow cytometer on anticoagulated $\left(\mathrm{K}_{2}\right.$ EDTA) whole blood using a clinically validated lyse no wash protocol. Briefly, $50 \mu \mathrm{L}$ of whole blood was added to BD Trucount ${ }^{\mathrm{TM}}$ absolute counting tubes, with $10 \mu \mathrm{L}$ of PerCP-anti-CD45 (clone 2D1), $10 \mu \mathrm{L}$ of PE-anti-CD3e (clone UCHT1) and $10 \mu \mathrm{L}$ of FITC-anti-CD57 (clone HNK-1) antibody and incubated for $10 \mathrm{~min}$ in the dark. The samples where then and lysed with $0.5 \mathrm{~mL}$ of BD FACS ${ }^{\mathrm{TM}}$ lysing solution and analyzed promptly. Lymphocytes were gated based on forward and side scatter, collecting a minimum of 1000 counting beads, and the cells of interested were identified as the $\mathrm{CD} 7^{+} / \mathrm{CD}^{-}$population. Counting beads in the Trucount $^{\mathrm{TM}}$ tubes were used to calculate the absolute number of $\mathrm{CD} 57^{+} / \mathrm{CD}^{-}$lymphocytes per $\mathrm{ml}$ of blood.

\section{Statistical methods}

Our dataset consisted of the four variables measured for 70 female controls, 70 male controls, 70 female cases, and 71 male cases. One instance of the IL-8 measure $(22,595,208 \mathrm{pg} / \mathrm{mL})$ was 700 -fold greater than the next highest IL-8 measure $(32,717 \mathrm{pg} / \mathrm{mL})$, and almost 12 standard deviations above the mean case IL- 8 measure. This outlier was excluded from the dataset, leaving 69 female cases and 71 male cases. The data were preliminary analyzed using a logistic regression model. Additionally, in order to explore if a diagnostic algorithm could be established, we performed a classification analysis using the respective clinical variables in combination with age and gender as the covariates and subject status (case or control) as the target variable.

\section{Results}

Distributions of the four variables were log-transformed and tested for normality. As none of the four distributions were normal, non-parametric statistical tests were performed. A simple forward and backward logistic regression was performed on the four biochemical parameters and the covariates age and gender. None of the four biochemical parameters were found to be in high correlation with each other, ranging between $[-0.26,0.61]$. The best model included the sCD14, PGE 2 , IL-8 measures with coefficients $0.002,0.249$, and 0.005 , respectively, and $\mathrm{p}$-values of $3 \times 10^{-7}, 1 \times 10^{-5}$, and $3 \times 10^{-3}$, respectively.

In order to establish if a potential diagnostic algorithm was feasible, we conducted a classification and regression tree (CART) analysis using $\mathrm{SCD} 14, \mathrm{PGE}_{2}$, IL-8 as predictive variables and subject status as the target variable. CART analysis utilizes recursive partitioning of these clinical variables into increasingly smaller sets of the dependent variable (case or control in our analysis). During each recursion, the binary splits for each dependent 
Table 2 CART analysis summary of ME cases and healthy controls

\begin{tabular}{llllc}
\hline Actual class & Total class & $\begin{array}{l}\text { Percent } \\
\text { correct (\%) }\end{array}$ & \multicolumn{2}{l}{ Predicted classes } \\
\cline { 3 - 5 } & & & ME case & Control \\
& & & $\mathbf{N = 1 3 9}$ & $\mathbf{N = 1 4 1}$ \\
\hline Case & 140 & 89.29 & 125 & 15 \\
Control & 140 & 90.00 & 14 & 126 \\
Total & 280 & & & \\
Average & & 89.64 & & \\
Overall correct & & 89.64 & & \\
Specificity & & 90.00 & & \\
Sensitivity & & 89.29 & & \\
Precision & & 89.93 & \\
F1 statistic & & 89.61 & \\
\hline
\end{tabular}

variable is examined and the split that optimizes the homogeneousness of the two resulting groups, with respect to the dependent variable is chosen [36]. CART analysis is well-suited for this investigation, as it produces an algorithm that is amenable for diagnostic data purposes. It is also able to classify systems that differ due to natural causes and determine the relative importance of different variables for identifying homogeneous groups within a data set [37].

Using the CART analysis with the Gini splitting method, a 16-node decision tree produced a set of "ifthen" logical (split) conditions, based on the biochemical parameters, that yielded approximately $90 \%$ specificity and sensitivity in distinguishing $\mathrm{ME}$ cases from controls (Table 2). Each node of the decision tree provided a decision metric based on the subject values of one of the three clinical parameters (Fig. 1). A detailed analysis of each node with the respective split values are given in Additional file 1: Figure S1.

We additionally conducted a CART analysis with all four clinical variables, as well as the demographic variables of age and gender; however, this analysis did not significantly improve the predictive outcome (data not shown).

\section{Discussion}

Diagnosing ME is problematic in that no disease-specific biological markers have been described; therefore, a diagnosis is made when a patient meets a combination of costly and subjective inclusion and exclusion criteria [11, 12, 38]. For this reason, a convenient diagnostic for ME would dramatically improve patient care and decrease medical costs. Such a diagnostic would also allow physicians and researchers to objectively follow the efficacy of new therapeutics during the course of clinical trials. With

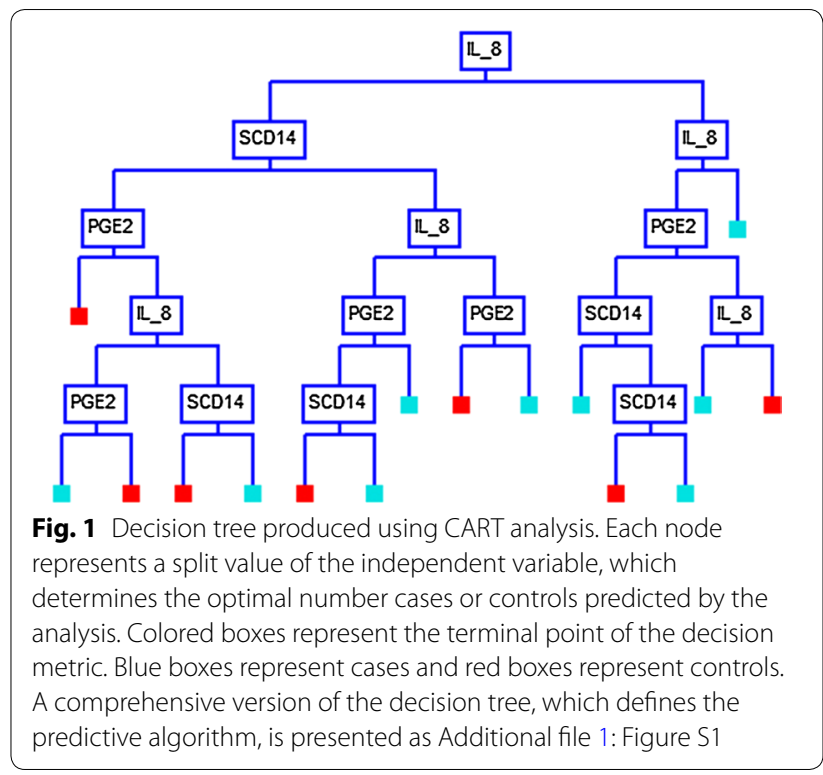

this in mind, we have conducted a retrospective analysis to assess the utility of four clinical laboratory parameters in diagnosing ME cases. Three of these were ultimately used to conduct a CART analysis in order to identify an algorithm that can assist physicians in the use of these parameters.

When we conducted our analysis, access to similar data from other disease cohorts was not available. These data would be necessary to show that the parameters can be used to distinguish ME from other diseases with overlapping comorbidities, and thus, represented the principal limitation to our study. Additionally, because this was a retrospective study that utilized existing data, we were not able to establish subgroups based on clinical presentations. The only data available were clinical laboratory data, demographic data and disease diagnosis. Although acquiring and screening specimens representing these other disease cohorts will be the focus of future studies, the data and results presented here are an important first step in the ultimate goal of developing a specific diagnostic for ME. This study also provides clear unequivocal evidence of the immunological underpinnings of ME.

In this study, we analyzed data from $140 \mathrm{ME}$ cases and 140 healthy controls subjects, composed of approximately half males and half females in each group. Using the two analytical methods, linear regression and CART, we determined that gender and age did not significantly impact the predictive model, nor did the inclusion of absolute $\mathrm{CD} 57^{+} / \mathrm{CD}^{-}$lymphocytes counts. The CD57 antigen is a sulfated glycan carbohydrate epitope and among circulating lymphocytes, is primarily expressed on mature NK cells and terminally differentiated $\mathrm{T}$ cells. 
Although its function on NK cells is still a subject of ongoing research, CD57 expression is also considered a marker for NK cells that are highly mature and terminally differentiated [39], and is also generally believed to reflect their immunosenescence [40]. NK cell dysfunction has been reported to associated with ME by several investigators [41, 42]; however, recent studies have brought into question their diagnostic potential [43]. While differences in $\mathrm{CD} 7^{+} / \mathrm{CD}^{-}$lymphocytes counts have been associated with other neuroimmune diseases [44], their inclusion in our study did not significantly improve its overall diagnostic ability. Nevertheless, there may be a number of reasons for this. In the present study, we limited our subjects to those with a confirmed diagnosis of ME, which by definition, implies that other potential causes have been ruled out [11]. Notwithstanding, when investigating diseases with overlapping or similar symptoms, including $\mathrm{CD} 57^{+} / \mathrm{CD}^{-}$lymphocyte counts may be beneficial. For instance, Blom et al. reported that tick-borne encephalitis virus-induced NK cell activation is primarily limited to differentiated $\mathrm{CD} 57^{+} / \mathrm{CD} 56^{\mathrm{dim}+}$ NK cells [45]. Additionally, $\mathrm{CD} 57^{+} \mathrm{NK}$ cells are routinely implicated in herpesvirus infections [46, 47]. Therefore, including this parameter may be of utility when establishing or ruling out an initial diagnosis of ME.

In this study, we utilized classification and regression tree CART analysis to produce a predictive binary decision tree, that defines the optimal values of each parameter as a branch point. Using serum IL-8 as the first node in the decision tree and with a cut-off value of $>137.5 \mathrm{pg} /$ $\mathrm{mL}, 109$ of the $140 \mathrm{ME}$ cases subjects were correctly categorized. Moreover, 132 of 140 controls were correctly categorized as having IL- 8 values of $\leq 137.5 \mathrm{pg} / \mathrm{mL}$ (Additional file 1: Figure S1).

IL-8 is a chemotactic factor that attracts leukocytes, such as neutrophils, basophils, and T-cells to sites of tissue injury and infection. Upregulation of IL-8 has also been reported in association with several chronic diseases such as autoimmune and inflammatory disease [48]. Multiple isoforms of IL-8 are produced through alternate splicing and proteolytic cleavage; a process that is largely cell-specific. For instance, the most common isoform in humans, IL-8(6-77), is produced primarily by monocytes and lymphocytes, while IL-8(1-77), which is produced by fibroblasts and endothelial cells, is likely the second most abundant form [49]. Notwithstanding, a wide variety of other cells express IL-8 including neutrophils, fibroblasts, mast cells, smooth muscle cells and dendritic cells [50-54]. Additionally, posttranslational modification of IL-8, such as citrullination or deamination, is known to lead to altered biological activity [55]. Understanding which isoform of IL-8, and which posttranslational modifications are most prevalent in ME may provide valuable insight into the underlying pathophysiology of the disease.

In our retrospective analysis, we observed IL-8 to be significantly upregulated in a large number of ME subjects; however, previous studies have reported inconsistent or contradictory results with respect to IL-8 $[19,23$, 56-58]. For instance, in one study, no difference in serum IL-8 levels were observed in ME cases when compared to healthy controls [16]; however, another study using the same analytical methods, showed significant differences between short-duration versus long-duration ME cases versus controls [15]. These discrepancies may be the result of patient selection methods, choice of sample matrix (i.e. serum vs. plasma, vs. mRNA) or analytical methods. Indeed, the heterogenous nature of the disease makes patient selection a perennial difficulty when investigating ME and the two aforementioned studies support this assertion, at least with respect to IL-8.

In that two previously mentioned studies utilized the same multiplex product (custom Luminex 51-plex manufactured by Affymetrix), and their mean ME results were significantly lower than that observed in our study, we speculated that the discrepancy may be inherent in assay systems. Bead-based and sandwich ELISAs rely on antibodies pairs that are specific for two different epitopes on the target protein, therefore, it is reasonable to conclude that some antibody pairs may not detect all isoforms of a protein. To explore this possibility, we purchased an Affymetrix ProcartaPlex ${ }^{\mathrm{TM}}$ Simplex IL-8 Luminex kit, which utilizes the same bead (region 27) as that used in the multiplex kit. We then screened the serum of $15 \mathrm{ME}$ cases that were part of the present study and also included two recombinant IL-8 isoforms as standards; IL-8(6-77) and IL-8(1-77). Both isoforms were detected by the assay; albeit, IL-8(1-77) was observed to be approximately $40 \%$ of that reported by the manufacturer $(1956 \mathrm{pg} / \mathrm{mL}$ observed vs $5000 \mathrm{pg} / \mathrm{mL}$ expected). We also screened the $15 \mathrm{ME}$ cases using a commercial ELISA kit (Invitrogen, IL-8 Human ELISA Kit) and observed the 15 ME cases to yield different results between the three assay methods, with the results produced by the Affymetrix kit being significantly lower than the other two methods, consistent with the discrepancy between our study and two previously mentioned studies (Additional file 2: Table S1). While we did not resolve the issue of potential IL- 8 isotype differences, it does suggest that the observed differences between the three studies are likely the result of a combination of factors, including patient selection and analytical methods. It also emphasizes the reliance of the methods described herein when implementing the predictive model as well as suggests further investigations with respect to IL-8 are warranted in ME. 
In additional to $\mathrm{CD} 57^{+} / \mathrm{CD}^{-}$lymphocytes and serum IL-8, we also investigated the utility of including $\mathrm{SCD} 14$ and $\mathrm{PGE}_{2}$ in our model. CD14, along with Toll-like receptor (TLR)-4 and lymphocyte antigen 96 (MD-2), forms the receptor complex that bind lipopolysaccharides (LPS) [59], which are found in the outer membrane of Gram-negative bacteria. Previous reports have identified sCD14 as a nonspecific marker of monocyte activation [60] as well as a surrogate marker of bacterial translocation in the gut [61]. Therefore, individuals with ME and who present with an upregulation of sCD14 are likely to have a GI comorbidity. Accordingly, sCD14 may be a useful biomarker for subgrouping ME cases, with irritable bowel syndrome. $\mathrm{PGE}_{2}$, on the other hand, regulates multiple aspects of inflammation and the functions of different immune cells [62]. It is generally acknowledged as a mediator of acute inflammation, stimulating chemotaxis and activation of mast cells, neutrophils, and macrophages, during the early stages of inflammation [63-65]. It also has the capacity promote the induction of suppressive IL-10 as well as the downregulation of several proinflammatory cytokines, thus suppressing nonspecific inflammation [62]. Although it can promote the activation, maturation and migration of professional antigen-presenting cells, it has been shown to suppress both innate and antigen-specific immunity at several levels $[62,66]$. Therefore, $\mathrm{PGE}_{2}$ has proinflammatory as well as immunosuppressive properties.

Our model showed that SCD14 can further subgroup ME cases with IL-8 levels that satisfy the following inequality: $22.0 \mathrm{pg} / \mathrm{mL}<\mathrm{IL}-8 \leq 137.5 \mathrm{pg} / \mathrm{mL}$. We also observed that $\mathrm{PGE}_{2}$ can be used to subgroup ME cases with IL-8 levels that satisfy the following inequality: $137.5 \mathrm{pg} / \mathrm{mL}<\mathrm{IL}-8 \leq 240.0 \mathrm{pg} / \mathrm{mL}$ (Additional file 1 : Figure S1). Additional combinations of IL-8, sCD14 and $\mathrm{PGE}_{2}$, as articulated in Additional file 1: Figure S1, can be used to further subgroup ME cases from healthy controls.

\section{Conclusions}

In summary, we have conducted a retrospective analysis of four clinical parameters from ME cases and healthy controls and have shown that three of these parameters can be used to delineate ME cases and controls with approximately $90 \%$ specificity and sensitivity using the analytical methods described herein. Further studies will be necessary to show if the proposed model will be useful in diagnosing ME from diseases with overlapping comorbidity.

\section{Additional files}

Additional file 1: Figure S1. Comprehensive version of the decision tree presented in Fig. 1

Additional file 2: Table S1. Comparison between three analytical methods. All values are $\mathrm{pg} / \mathrm{mL}$.

\section{Abbreviations \\ CART: classification and regression tree; CXCL8: chemokine (C-X-C motif) ligand 8; GWAS: genome-wide association studies; HIPAA: Health Insurance Portability and Accountability Act; IL: interleukin; IRB: Institutional Review Board; LPS: lipopolysaccharides; ME: myalgic encephalomyelitis; PGE$_{2}$ : prosta- glandin E2; SCD14: soluble cluster of differentiation 14; TLR: toll-like receptor.}

\section{Authors' contributions}

KDM diagnosed patients and chose laboratory parameters to investigate, TM performed clinical laboratory testing, VCL performed confirmatory laboratory testing, KS, collected and organized data, KAS and VCL performed data analysis, TM and VCL wrote the manuscript. All authors read and approved the final manuscript.

\section{Author details}

${ }^{1}$ Himmunitas Foundation, de Tyraslaan 111, 1120 Brussels, Belgium. ${ }^{2}$ R.E.D. Laboratories, Z.1 Research park 100, 1731 Zellik, Belgium. ${ }^{3}$ Himmunitas Clinic, de Tyraslaan 111, 1120 Brussels, Belgium. ${ }^{4}$ Desert Research Institute, 2350 Raggio Pkwy, Reno, NV 89512, USA. ${ }^{5}$ Department of Microbiology and Immunology, University of Nevada, Reno, School of Medicine, Reno, NV, USA.

\section{Acknowledgements}

We are grateful to Nossa Van den Vonder for her assistance in collecting the data and to Carli Kinne for her assistance with the human subject protocol.

\section{Competing interests}

KDM and TM are employees of their respective institutions, which charge for their services. R.E.D. Laboratories is a commercial laboratory which offers the diagnostics used in this report on a fee for service basis.

\section{Availability of data and materials}

The datasets used and/or analyzed during the current study are available from the corresponding author on reasonable request.

\section{Consent for publication}

Not applicable.

\section{Ethics approval and consent to participate}

Retrospective analyses of existing clinical data were conducted under a HIPAA authorization waiver, as determined by the University of Nevada, Reno Institutional Review Board (IRB) [Protocol 1213405-1].

Funding

This study was internally funded.

\section{Publisher's Note}

Springer Nature remains neutral with regard to jurisdictional claims in published maps and institutional affiliations.

Received: 1 September 2018 Accepted: 14 November 2018 Published online: 21 November 2018

\section{References}

1. Klimas NG, Koneru AO. Chronic fatigue syndrome: inflammation, immune function, and neuroendocrine interactions. Curr Rheumatol Rep. 2007:9:482-7.

2. Lin JM, Resch SC, Brimmer DJ, Johnson A, Kennedy S, Burstein N, Simon CJ. The economic impact of chronic fatigue syndrome in Georgia: direct and indirect costs. Cost Eff Resour Alloc. 2011;9:1. 
3. Jason LA, Benton MC, Valentine L, Johnson A, Torres-Harding S. The economic impact of ME/CFS: individual and societal costs. Dyn Med. 2008;7:6.

4. Bell KM, Cookfair D, Bell DS, Reese P, Cooper L. Risk factors associated with chronic fatigue syndrome in a cluster of pediatric cases. Rev Infect Dis. 1991;13(Suppl 1):S32-8.

5. Racciatti D, Vecchiet J, Ceccomancini A, Ricci F, Pizzigallo E. Chronic fatigue syndrome following a toxic exposure. Sci Total Environ. 2001;270:27-31.

6. Jason LA, Porter N, Hunnell J, Rademaker A, Richman JA. CFS prevalence and risk factors over time. J Health Psychol. 2011;16:445-56.

7. Albright F, Light K, Light A, Bateman L, Cannon-Albright LA. Evidence for a heritable predisposition to chronic fatigue syndrome. BMC Neurol. 2011;11:62.

8. Schlauch KA, Khaiboullina SF, De Meirleir KL, Rawat S, Petereit J, Rizvanov AA, Blatt N, Mijatovic T, Kulick D, Palotas A, Lombardi VC. Genomewide association analysis identifies genetic variations in subjects with myalgic encephalomyelitis/chronic fatigue syndrome. Transl Psychiatry. 2016;6:e730.

9. Rajeevan MS, Dimulescu I, Murray J, Falkenberg VR, Unger ER. Pathwayfocused genetic evaluation of immune and inflammation related genes with chronic fatigue syndrome. Hum Immunol. 2015;76:553-60.

10. Buchwald D, Herrell R, Ashton S, Belcourt M, Schmaling K, Sullivan P, Neale M, Goldberg J. A twin study of chronic fatigue. Psychosom Med. 2001;63:936-43.

11. Carruthers BM, van de Sande MI, De Meirleir KL, Klimas NG, Broderick G, Mitchell T, Staines D, Powles AC, Speight N, Vallings R, et al. Myalgic encephalomyelitis: international consensus criteria. J Intern Med. 2011;270:327-38.

12. Carruthers B, Jain AK, De Meirleir K, Peterson D, Klimas N, Lerner A, Bested A, Flor-Henry P, Joshi P, Powles A, et al. Myalgic encephalomyelitis/chronic fatigue syndrome: clinical working case definition, diagnostic and treatment protocols. J Chronic Fatigue Syndrome. 2003;11:1-12.

13. Maclachlan L, Watson S, Gallagher P, Finkelmeyer A, Jason LA, Sunnquist $M$, Newton JL. Are current chronic fatigue syndrome criteria diagnosing different disease phenotypes? PLOS ONE. 2017;12:e0186885.

14. Stringer EA, Baker KS, Carroll IR, Montoya JG, Chu L, Maecker HT, Younger JW. Daily cytokine fluctuations, driven by leptin, are associated with fatigue severity in chronic fatigue syndrome: evidence of inflammatory pathology. J Transl Med. 2013;11:93.

15. Hornig M, Montoya JG, Klimas NG, Levine S, Felsenstein D, Bateman L, Peterson DL, Gottschalk CG, Schultz AF, Che X, et al. Distinct plasma immune signatures in ME/CFS are present early in the course of illness. Sci Adv. 2015;1:e1400121.

16. Montoya JG, Holmes TH, Anderson JN, Maecker HT, Rosenberg-Hasson Y, Valencia IJ, Chu L, Younger JW, Tato CM, Davis MM. Cytokine signature associated with disease severity in chronic fatigue syndrome patients. Proc Natl Acad Sci USA. 2017;114:E7150-8

17. Naviaux RK, Naviaux JC, Li K, Bright AT, Alaynick WA, Wang L, Baxter A, Nathan N, Anderson W, Gordon E. Metabolic features of chronic fatigue syndrome. Proc Natl Acad Sci USA. 2016;113:E5472-80.

18. Nagy-Szakal D, Barupal DK, Lee B, Che X, Williams BL, Kahn EJR, Ukaigwe JE, Bateman L, Klimas NG, Komaroff AL, et al. Insights into myalgic encephalomyelitis/chronic fatigue syndrome phenotypes through comprehensive metabolomics. Sci Rep. 2018:8:10056.

19. Fletcher MA, Zeng XR, Barnes Z, Levis S, Klimas NG. Plasma cytokines in women with chronic fatigue syndrome. J Transl Med. 2009;7:96.

20. Kerr JR, Tyrrell DA. Cytokines in parvovirus B19 infection as an aid to understanding chronic fatigue syndrome. Curr Pain Headache Rep. 2003:7:333-41.

21. Nakamura T, Schwander SK, Donnelly R, Ortega F, Togo F, Broderick G, Yamamoto Y, Cherniack NS, Rapoport D, Natelson BH. Cytokines across the night in chronic fatigue syndrome with and without fibromyalgia. Clin Vaccine Immunol. 2010;17:582-7.

22. Patarca R. Cytokines and chronic fatigue syndrome. Ann N Y Acad Sci. 2001:933:185-200.

23. Khaiboullina SF, DeMeirleir KL, Rawat S, Berk GS, Gaynor-Berk RS, Mijatovic T, Blatt N, Rizvanov AA, Young SG, Lombardi VC. Cytokine expression provides clues to the pathophysiology of Gulf War illness and myalgic encephalomyelitis. Cytokine. 2015;72:1-8.
24. Reynolds GK, Lewis DP, Richardson AM, Lidbury BA. Comorbidity of postural orthostatic tachycardia syndrome and chronic fatigue syndrome in an Australian cohort. J Intern Med. 2014:275:409-17.

25. He J, Hollingsworth KG, Newton JL, Blamire AM. Cerebral vascular control is associated with skeletal muscle $\mathrm{pH}$ in chronic fatique syndrome patients both at rest and during dynamic stimulation. Neuroimage Clin. 2013;2:168-73.

26. Kalinski P. Regulation of immune responses by prostaglandin E2. J Immunol. 2012;188:21-8.

27. Koshikawa N, Tatsunuma T, Furuya K, Seki K. Prostaglandins and premenstrual syndrome. Prostaglandins Leukot Essent Fatty Acids. 1992;45:33-6.

28. Horrobin DF. The role of essential fatty acids and prostaglandins in the premenstrual syndrome. J Reprod Med. 1983;28:465-8.

29. Nielsen CM, White MJ, Goodier MR, Riley EM. Functional significance of CD57 expression on human NK cells and relevance to disease. Front Immunol. 2013:4:422.

30. Loebel M, Grabowski P, Heidecke H, Bauer S, Hanitsch LG, Wittke K, Meisel C, Reinke P, Volk HD, Fluge O, et al. Antibodies to beta adrenergic and muscarinic cholinergic receptors in patients with chronic fatigue syndrome. Brain Behav Immun. 2016;52:32-9.

31. Maes M, Ringel K, Kubera M, Anderson G, Morris G, Galecki P, Geffard M. In myalgic encephalomyelitis/chronic fatigue syndrome, increased autoimmune activity against 5-HT is associated with immuno-inflammatory pathways and bacterial translocation. J Affect Disord. 2013;150:223-30.

32. Morris G, Berk M, Galecki P, Maes M. The emerging role of autoimmunity in myalgic encephalomyelitis/chronic fatigue syndrome (ME/cfs). Mol Neurobiol. 2014:49:741-56.

33. Singh S, Stafford P, Schlauch KA, Tillett RR, Gollery M, Johnston SA, Khaiboullina SF, De Meirleir KL, Rawat S, Mijatovic T, et al. Humoral immunity profiling of subjects with myalgic encephalomyelitis using a random peptide microarray differentiates cases from controls with high specificity and sensitivity. Mol Neurobiol. 2018;55:633-41.

34. Sotzny F, Blanco J, Capelli E, Castro-Marrero J, Steiner S, Murovska M, Scheibenbogen C, European Network on MC. Myalgic encephalomyelitis/chronic fatigue syndrome-evidence for an autoimmune disease. Autoimmun Rev. 2018:17:601-9.

35. Blomberg J, Gottfries CG, Elfaitouri A, Rizwan M, Rosen A. Infection elicited autoimmunity and myalgic encephalomyelitis/chronic fatigue syndrome: an explanatory model. Front Immunol. 2018;9:229.

36. De'ath G, Fabricius KE. Classification and regression trees: a powerful yet simple technique for ecological data analysis. Ecology. 2000;81:3178-92.

37. Prasad AM. Macroscale intraspecific variation and environmental heterogeneity: analysis of cold and warm zone abundance, mortality, and regeneration distributions of four eastern US tree species. Ecol Evol. 2015;5:5033-48.

38. Fukuda K, Straus SE, Hickie I, Sharpe MC, Dobbins JG, Komaroff A. The chronic fatigue syndrome: a comprehensive approach to its definition and study. International Chronic Fatigue Syndrome Study Group. Ann Intern Med. 1994;121:953-9.

39. Lopez-Verges S, Milush JM, Pandey S, York VA, Arakawa-Hoyt J, Pircher H, Norris PJ, Nixon DF, Lanier LL. CD57 defines a functionally distinct population of mature NK cells in the human CD56dimCD16+ NK-cell subset. Blood. 2010:116:3865-74.

40. Stricker RB, Winger EE. Decreased CD57 lymphocyte subset in patients with chronic Lyme disease. Immunol Lett. 2001;76:43-8.

41. Brenu EW, van Driel ML, Staines DR, Ashton KJ, Hardcastle SL, Keane J, Tajouri L, Peterson D, Ramos SB, Marshall-Gradisnik SM. Longitudinal investigation of natural killer cells and cytokines in chronic fatigue syndrome/myalgic encephalomyelitis. J Transl Med. 2012;10:88.

42. Brenu EW, Staines DR, Baskurt OK, Ashton KJ, Ramos SB, Christy RM, Marshall-Gradisnik SM. Immune and hemorheological changes in chronic fatigue syndrome. J Transl Med. 2010;8:1.

43. Theorell J, Bileviciute-Ljungar I, Tesi B, Schlums H, Johnsgaard MS, AsadiAzarbaijani B, Bolle Strand E, Bryceson YT. Unperturbed cytotoxic lymphocyte phenotype and function in myalgic encephalomyelitis/chronic fatigue syndrome patients. Front Immunol. 2017:8:723.

44. Siniscalco D, Mijatovic T, Bosmans E, Cirillo A, Kruzliak P, Lombardi VC, De Meirleir K, Antonucci N. Decreased numbers of CD57+CD3- cells identify potential innate immune differences in patients with autism spectrum disorder. Vivo. 2016;30:83-9. 
45. Blom K, Braun M, Pakalniene J, Lunemann S, Enqvist M, Dailidyte $L$, Schaffer M, Lindquist L, Mickiene A, Michaelsson J, et al. NK cell responses to human tick-borne encephalitis virus infection. J Immunol. 2016;197:2762-71.

46. Nerreter T, Zeiss S, Herrmann T, Einsele H, Seggewiss-Bernhardt R. Robust 8-color flow cytometry panel reveals enhanced effector function of NKG2C(+) CD57(+) FcepsilonRgamma(-) NK cells in CMV seropositive human blood donors. Immunobiology. 2017;222:719-25.

47. Saboia-Dantas CJ, Coutrin de Toledo LF, Siqueira JF Jr, Sampaio-Filho HR, Carvalho JJ, Pereira MJ Jr. Natural killer cells and alterations in collagen density: signs of periradicular herpesvirus infection? Clin Oral Investig. 2008;12:129-35.

48. Russo RC, Garcia CC, Teixeira MM, Amaral FA. The CXCL8/L-8 chemokine family and its receptors in inflammatory diseases. Expert Rev Clin Immunol. 2014;10:593-619

49. Kristensen MS, Paludan K, Larsen CG, Zachariae CO, Deleuran BW, Jensen PK, Jorgensen P, Thestrup-Pedersen K. Quantitative determination of IL-1 alpha-induced IL-8 mRNA levels in cultured human keratinocytes, dermal fibroblasts, endothelial cells, and monocytes. J Invest Dermatol. 1991;97:506-10.

50. Lim CP, Phan TT, Lim IJ, Cao X. Cytokine profiling and Stat3 phosphorylation in epithelial-mesenchymal interactions between keloid keratinocytes and fibroblasts. J Invest Dermatol. 2009;129:851-61.

51. Moller A, Lippert U, Lessmann D, Kolde G, Hamann K, Welker P, Schadendorf D, Rosenbach T, Luger T, Czarnetzki BM. Human mast cells produce IL-8. J Immunol. 1993;151:3261-6.

52. Smedman C, Gardlund B, Nihlmark K, Gille-Johnson P, Andersson J, Paulie S. ELISpot analysis of LPS-stimulated leukocytes: human granulocytes selectively secrete IL-8, MIP-1 beta and TNF-alpha. J Immunol Methods. 2009;346:1-8

53. Sandor N, Pap D, Prechl J, Erdei A, Bajtay Z. A novel, complement-mediated way to enhance the interplay between macrophages, dendritic cells and T Iymphocytes. Mol Immunol. 2009;47:438-48.

54. Vanaudenaerde BM, Wuyts WA, Dupont $L$, Van Raemdonck DE, Demedts MM, Verleden GM. Interleukin-17 stimulates release of interleukin-8 by human airway smooth muscle cells in vitro: a potential role for interleukin-17 and airway smooth muscle cells in bronchiolitis obliterans syndrome. J Heart Lung Transplant. 2003;22:1280-3.
55. Proost P, Loos T, Mortier A, Schutyser E, Gouwy M, Noppen S, Dillen C, Ronsse I, Conings R, Struyf S, et al. Citrullination of CXCL8 by peptidylarginine deiminase alters receptor usage, prevents proteolysis, and dampens tissue inflammation. J Exp Med. 2008;205:2085-97.

56. Hardcastle SL, Brenu EW, Johnston S, Nguyen T, Huth T, Ramos S, Staines D, Marshall-Gradisnik S. Serum immune proteins in moderate and severe chronic fatigue syndrome/myalgic encephalomyelitis patients. Int J Med Sci. 2015;12:764-72.

57. Neu D, Mairesse O, Montana X, Gilson M, Corazza F, Lefevre N, Linkowski P, Le Bon O, Verbanck P. Dimensions of pure chronic fatigue: psychophysical, cognitive and biological correlates in the chronic fatigue syndrome. Eur J Appl Physiol. 2014;114:1841-51.

58. Russell L, Broderick G, Taylor R, Fernandes H, Harvey J, Barnes Z, Smylie A, Collado F, Balbin EG, Katz BZ, et al. Illness progression in chronic fatigue syndrome: a shifting immune baseline. BMC Immunol. 2016;17:3.

59. Kitchens RL. Role of CD14 in cellular recognition of bacterial lipopolysaccharides. Chem Immunol. 2000;74:61-82.

60. Shive CL, Jiang W, Anthony DD, Lederman MM. Soluble CD14 is a nonspecific marker of monocyte activation. AIDS. 2015;29:1263-5.

61. Stehle JR Jr, Leng X, Kitzman DW, Nicklas BJ, Kritchevsky SB, High KP Lipopolysaccharide-binding protein, a surrogate marker of microbial translocation, is associated with physical function in healthy older adults. J Gerontol A Biol Sci Med Sci. 2012;67:1212-8.

62. Phipps RP, Stein SH, Roper RL. A new view of prostaglandin E regulation of the immune response. Immunol Today. 1991;12:349-52.

63. Yu Y, Chadee K. Prostaglandin E2 stimulates IL-8 gene expression in human colonic epithelial cells by a posttranscriptional mechanism. J Immunol. 1998;161:3746-52.

64. Nakayama T, Mutsuga N, Yao L, Tosato G. Prostaglandin E2 promotes degranulation-independent release of MCP-1 from mast cells. J Leukoc Biol. 2006;79:95-104.

65. Weller CL, Collington SJ, Hartnell A, Conroy DM, Kaise T, Barker JE, Wilson MS, Taylor GW, Jose PJ, Williams TJ. Chemotactic action of prostaglandin E2 on mouse mast cells acting via the PGE2 receptor 3. Proc Natl Acad Sci USA. 2007:104:11712-7.

66. Harris SG, Padilla J, Koumas L, Ray D, Phipps RP. Prostaglandins as modulators of immunity. Trends Immunol. 2002;23:144-50.

Ready to submit your research? Choose BMC and benefit from:

- fast, convenient online submission

- thorough peer review by experienced researchers in your field

- rapid publication on acceptance

- support for research data, including large and complex data types

- gold Open Access which fosters wider collaboration and increased citations

- maximum visibility for your research: over $100 \mathrm{M}$ website views per year

At BMC, research is always in progress.

Learn more biomedcentral.com/submissions 